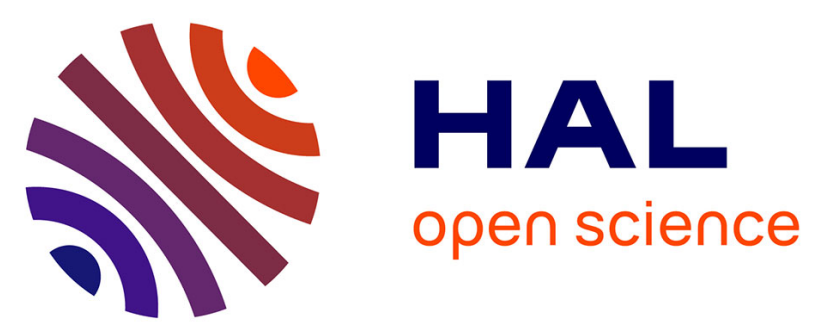

\title{
I'm free but I'll comply with your request: generalization and multidimensional effects of the "evoking freedom" technique
}

Nicolas Guéguen, Robert-Vincent Joule, Séverine Halimi-Falkowicz, Alexandre Pascual, Jacques Fischer-Lokou, Maya Dufourcq-Brana

\section{To cite this version:}

Nicolas Guéguen, Robert-Vincent Joule, Séverine Halimi-Falkowicz, Alexandre Pascual, Jacques Fischer-Lokou, et al.. I'm free but I'll comply with your request: generalization and multidimensional effects of the "evoking freedom" technique. Journal of Applied Social Psychology, 2013, 43 (1), pp.116-137. 10.1111/j.1559-1816.2012.00986.x . hal-02069189

\section{HAL Id: hal-02069189 \\ https://hal.univ-rennes2.fr/hal-02069189}

Submitted on 15 Mar 2019

HAL is a multi-disciplinary open access archive for the deposit and dissemination of scientific research documents, whether they are published or not. The documents may come from teaching and research institutions in France or abroad, or from public or private research centers.
L'archive ouverte pluridisciplinaire HAL, est destinée au dépôt et à la diffusion de documents scientifiques de niveau recherche, publiés ou non, émanant des établissements d'enseignement et de recherche français ou étrangers, des laboratoires publics ou privés. 


\title{
I'm free but I'Il comply with your request: generalization and multidimensional effects of the "evoking freedom" technique
}

\author{
Nicolas Guéguen1', Robert-Vincent Joule², Séverine Halimi-Falkowicz ${ }^{2}$, Alexandre Pascual², \\ Jacques Fischer-Lokou', Maya Dufourcq-Brana ${ }^{1}$ \\ 'Université de Bretagne-Sud \\ ${ }^{2}$ Université de Provence \\ ${ }^{3}$ Université de Bordeaux 2
}

\author{
Correspondence concerning this article should \\ be addressed to Nicolas Guéguen, Social \\ Sciences Department, Université de \\ Bretagne-Sud, rue de la loi, Vannes 56620, \\ France. E-mail: nicolas.gueguen@univ-ubs.fr
} doi: 10.1111/j.1559-1816.2012.00986.x

\begin{abstract}
The "evoking freedom" technique is a verbal compliance procedure that solicits someone to comply with a request by simply telling them they are free to accept or to refuse the request. The measure of the efficiency of this technique on compliance with large samples and the evaluation of its influence on various requests was tested in the first set of experiments. This technique was found to be efficient in increasing the number of people who agreed to give money to a requester, the number of smokers who agreed to give a cigarette, passersby who agreed to respond to a survey, and homeowners who agreed to buy pancakes. In the second set of experiments in which the mode of interaction between the requester and the person solicited was tested, the "evoking freedom" technique was found to be associated with greater compliance with a request addressed by mail and through face-to-face, phone-tophone, or computer-mediated interaction. The third set of experiments tested the effect of semantic variations of the "evoking freedom" technique and the weight of the repetition of the semantic evocation of freedom. These later experiments that used various phrases evoking the freedom to comply were found to be associated with greater compliance. Moreover, a double evocation of freedom was associated with even greater compliance than a single evocation. The importance of this technique for commitment communication is discussed.
\end{abstract}

To gain compliance with a request, many techniques exist in social psychology literature (see Pratkanis, 2007, for a review). Many of these techniques use sequential requests: the foot-in-the-door technique (Freedman \& Fraser, 1966), the door-in-the-face technique (Cialdini et al., 1975), the lowball tactic (Cialdini, Cacioppo, Basset, \& Miller, 1978), the lure (Joule, Gouilloux, \& Weber, 1989), and the 1-in-5 prize tactic (Horvitz \& Pratkanis, 2002). Some of them use ingratiation techniques such as flattery (Dunyon, Gossling, Willden, \& Seiter, 2010), incidental similarity (Burger, Messian, Patel, del Prado, \& Anderson, 2004), or mimicry (Van Baaren, Holland, Kawakami, \& Van Knippenberg, 2004). Others use nonverbal behaviors displayed by the solicitor such as tactile contact (Kleinke, 1977), smile (Solomon et al., 1981), or gaze (Kleinke, 1980).

Pratkanis (2007) identified 107 social influence tactics published in the literature. Of course, theoretical mecha- nisms associated with the efficiency of these various techniques are different and the method used to gain compliance differs between these various techniques. However, in spite of the methodological differences, these various techniques have something in common: At each step of the procedure, the participant is free to accept or to refuse to comply with the request. No pressure or external factors (e.g., incentives) were used at any given time to increase participants' compliance. In most of the techniques, requests were tested to enhance compliance rate and traditionally ended with phrases such as "you are free to accept or not," "it's up to you," "it's up to you to choose ...," "do as you like," and so on. But, such phrases are not trivial given the fact that the feeling that someone is free to comply or not with a request is a requirement to obtain compliance.

Two theoretical mechanisms can be used to explain the possible effects of such sentences on compliance. One 
theory that could explain the efficiency of such sentences on compliance is the reactance theory (Brehm \& Brehm, 1981; Wicklund, 1974). This theory assumes that people feel free to do certain things. When these perceived freedoms are threatened, people are motivated to restore them. When someone is solicited by a stranger, this solicitation probably elicits some reactance because the person solicited is perhaps busy, is frequently solicited day after day, likes to be in peace... Using a phrase that states that the participant is free to comply could decrease the reactance activated by the request that led, in return, to increase the probability to comply with this request.

The second explanation is associated with commitment theory. Kiesler (1971) and Kiesler and Sakumura (1966) have stated that to obtain a commitment from an individual to perform an expected act, it was necessary to increase the degree of commitment. There are several methods to increase commitment, but, for these authors, one of the most important would be to increase the degree of volition perceived by the individual in performing the expected behavior. Joule and Beauvois (1998) also stated, without any empirical evaluation, that this feeling of volition perceived by a person could be activated by using a phrase that states that the participant is free to comply or not. By this way, perceived free choice would be a condition for commitment effects and this perception could be activated by verbal content.

Without testing this specific aspect of the semantic evocation of freedom, some compliance techniques exist in social psychology literature that show that a positive effect on a participant's compliance is obtained only by using specific phrases. Cialdini and Schroeder (1976) have found that the addition of the phrase "even a penny helps" in a request for the profit of a charitable organization led to an increase in the amount of donations. This simple phrase also increases the number of donors (Reeves, Macolini, \& Martin, 1987; Reeves \& Saucer, 1993). Enzle and Harvey (1982) showed that indirect negation in a rhetorical request (e.g., "You will help me, won't you?") elicited a greater amount of help than either a direct negation in a rhetorical request (e.g., "Won't you help me?") or a control positive form (e.g., "Will you help me?"). The "foot-in-the-mouth" technique (Howard, 1990) is also a good tactic to elicit greater compliance with a request. This technique, which consists of asking someone how he/she feels, and to wait for the response, is associated with greater compliance with a following request than when the requester does not wait for the response or when this question is not used in the interaction. Several studies found that this technique increases compliance with various types of requests (Aune \& Basil, 1994; Dolinski, Nawrat, \& Rudak, 2001; Fointiat, 2000). Similarly, Burger (1986) succeeded in obtaining more purchases from participants in his experiment when he first gave a price for a product to a customer, and then, having left him/her some seconds, he apparently did not offer the remaining content of the offer, instead saying, "and that's not all." He observed repeatedly that this method, which was called the "that's-not-all" technique, turns out to be more effective than a situation where no decomposition of the contents of the offer was made.

So, overall, the latter techniques seem to attest that the several apparently innocuous semantic characteristics of a request can increase a participant's compliance. Of course, these tactics only prove that some phrases increase compliance with a request but do not prove that semantic evocation of freedom to comply is associated with greater effective compliance with a request. In order to test the specific influence of the semantic evocation of freedom, Guéguen and Pascual (2000) asked passersby in the street to give them money. In the experimental condition, their request ended by the phrase, "but you are free to accept or to refuse," whereas this phrase was not used in the control condition. They found that $10 \%$ of the solicited participants complied with the request in the control condition, whereas $47.5 \%$ accepted in the experimental condition. This technique, called by these authors the "but you are free" technique, leads not only to increasing compliance with a request, but also to increasing subject involvement. These authors have also found in their experiment that the average amount of donations granted by the subjects was higher in the experimental condition than in the control condition. Thus, this experiment seems to show empirically that the hypothetical statement of Joule and Beauvois (1998) saying that using a phrase that states that the participant is free or not to comply is associated with greater compliance with the request.

The series of experiments presented in this article was designed to investigate several aspects of the "evoking freedom" technique found by Guéguen and Pascual (2000) and initially called the "but you are free ..." technique. First, we wanted to show if we could replicate the findings observed from these authors given the fact that their research was performed with small samples and was associated with some possible methodological bias. Experiment 1 was conducted to evaluate the efficiency and the magnitude of the "evoking freedom" technique. Second, we wanted to know the extent of the request that could be affected by the "evoking freedom" request. So, Experiments 2-9 were performed in order to evaluate the type of requests affected by the "evoking freedom" technique. In these experiments, various dependent variables were measured: request for money, for a cigarette, for participation in various types of surveys, for sorting household wastes, and for buying some products. Experiments 10 and 11 examined different freedom-inducing phrases in order to test if the same efficiency is obtained with different verbal expressions that are used in everyday life to let someone know that he/she is free to do something or not. Finally, Experiments 12 and 13 were 
aimed at testing the role of the repetition of the "evoking freedom" phrase all along the request. Indeed, with several compliance techniques (Pratkanis, 2007) when the requester repeated the initial request twice rather than just saying it once, more compliance with the final request was found; thus, to know if the same effect occurred when, throughout the request, the phrase that stated that the participant was free to accept or to refuse was repeated twice instead of just being said once.

All the experiments were designed as field studies and were carried out in large- or middle-sized cities in France: Vannes and Lorient in Brittany (Experiments 1, 3, 5, 7), Bordeaux (Experiments 4, 6), and Aix-en-Provence (Experiments 2, 10, 11, 12, 13). Two experiments (Experiments 8, 9) were conducted in two business companies specialized in online marketing and sales. In most experiments, participants were solicited in the street when walking alone (Experiments 1, 3, $4,10,11,12,13)$, or students were solicited on campus (Experiment 2), while others were solicited at home (Experiments 5, 6, 7, 9). In one experiment, people were solicited through their electronic addresses available in a database of an association (Experiment 8). In another experiment (Experiment 9), participants were solicited by mail with the help of their postal address, while in another experiment (Experiment 7) participants were selected from phone books and solicited by phone.

The objective of the first experiment was to replicate the results obtained by Guéguen and Pascual (2000) by using a large sample size and reducing experimental bias. Indeed, in Guéguen and Pascual's study, the sample size was small (40 participants), and when examining the effect of the two experimental conditions on the amount of money donated by the participants, only 4 people were tested (10\% complied among 40 participants tested) in the control condition. A possible methodological bias was also associated. In their experiment, if four confederates ( 2 men and 2 women) were used, some of them ( 1 woman and 1 man) tested participants only in the experimental condition, whereas the other two ( 1 woman and 1 man) tested the participants only in the control condition. Again, a possible bias related to the confederates used in one condition compared with the other could preclude the results. Last, the selection of the participants in the two experimental conditions was not made according to a random repartition. So, in order to eliminate a possible confederate bias, it was necessary to conduct another experiment with a large number of confederates and with each confederate soliciting the participants in both conditions. So, in this experiment, more than 100 male and female confederates were instructed to solicit several thousands of passersby in the street for money. Depending on the case, confederates asked participants for money by using, or not, the phrase "but you are free to accept or to refuse" in the verbal content of their request.

\section{Experiment 1: Replicating the original "evoking freedom" tactic}

\section{Method}

\section{Participants}

The participants were 1,080 men and 1,080 women (estimated age range 30-50 years old), walking alone in the street of two towns (between 60,000 and 70,000 inhabitants) situated on the south coast of Brittany in France.

\section{Procedure}

A total of 108 confederates ( 49 men and 59 women) (average age 20-22 years old) took a role in this experiment. All the confederates were undergraduate students in Business Management and the experiment was presented as a field exercise for selling. They were neatly dressed and in a traditional way for young people of their age range (jeans/sneakers/T-shirt). The experiment took place in a mall during particularly sunny spring days. Each confederate was instructed to test ten passersby (five men and five women) in the experimental condition and ten passersby (five men and five women) in the control condition. A confederate approached a participant after counting the passage of a definite number of pedestrians in a defined zone. If the subject was a child or a teenager or an elderly man/woman or a group, the confederate approached the person coming just after so that he/she corresponded to the expected profile (a man or a woman aged approximately 30-50 years old). In the control condition, the confederate approached the participant by saying to him or her politely: "Sorry Madam/Sir, would you have some change for the bus, please?" In the experimental condition, with the same tone the confederate asked the following request: "Sorry Madam/ Sir, would you have some change for the bus, please? But you are free to accept or to refuse" ("Mais vous êtes libre d'accepter ou de refuser" in French). The confederate then estimated if the participant agreed or not to his/her request. In the case of a positive answer, the confederate waited until the participant gave him/her the money. The confederate estimated the amount and then gave back the sum to the participant. All participants were debriefed in the same way whether or not they agreed to the request. They were told that they had participated in an experiment on social behavior testing the effect of verbal request on compliance. A preprinted information form was then given to the participant who was asked to provide information for the experiment (name, age, address, phone number). Information concerning the role of the experimenter, the address of our laboratory website, and the personal phone number of the director of the laboratory was also included on the form. This was done following the recommendations of the ethical committee of the laboratory concerning the project. To date (the experiment was carried 
out in summer 2007), no one has phoned to obtain information about this research and some of the participants $(n=117)$ have offered to participate in future research.

\section{Results}

The percentages and number of participants who complied with the request for money addressed by the confederates and the amount of money given are shown in Table 1.

With the number of participants agreeing to the request, a log-linear analysis of the 2 (participant sex) $\times 2$ (experimental condition $) \times 2$ (compliance) design revealed only one significant effect, the interaction between the experimental conditions and the participant's compliance with the request, $\chi^{2}(1, n=2,160)=155.89, p<.001, \varphi=.28$. More participants in the experimental group (40.6\%) than in the control group $(16.4 \%)$ complied with the confederate's donation request. Using the amount of money per gift as the dependent variable, a 2 (participant sex) $\times 2$ (experimental condition) analysis of variance was performed. A main effect of the experimental conditions was found, $F(1,612)=130.54$, $p<.001, \eta^{2}=.413$, revealing that the amount of money donated by the participants was significantly higher in the "but you are free ..." condition than in the control condition (\$1.58 vs. \$1.04). A main effect of the participants gender was found, $F(1,612)=20.31, p<.001, \eta^{2}=.103$. However, no interaction effect between the participant sex and the experimental condition was found. Male participants appeared to be more generous (\$1.55) than female participants (\$1.32).

\section{Discussion}

With a very large number of participants and with a high number of confederates used, the data confirmed the tendency found by Guéguen and Pascual (2000). However, the sample size and the procedures used here prevented some possible biases associated with the attractiveness of the requester or with the selection of the participants in the experimental conditions. Thus, it can safely be advanced that a request for help associated with a phrase that stated that someone is free to accept or to refuse to help the solicitor was associated with greater compliance with the request than when this phrase was not added to it. With participants who agreed to the request, it was also found that adding that someone is free to accept or to refuse is associated with a higher level of compliance. Indeed, in the "evoking freedom" condition, participants gave more money to the requester than in the control condition. Again, these results confirm the data of Guéguen and Pascual (2000), but with more sizeable samples, because in Guéguen and Pascual's study only 4 participants agreed to the request in the control condition and 19 in the experimental condition, whereas in the latter experiment, 177 participants agreed to the request in the control condition and 439 in the experimental condition. In this experiment, the level of help was greater in both conditions than in Guéguen and Pascual's study (\$.48 in the control condition and \$1.04 in the experimental condition). This effect could be explained by the recent money transition in France and in Europe from French Francs to Euros. However, in spite of this money change, in both experiments, participants gave more frequently and gave more generously. In many cases where "money-given" is used as the dependent variable, the influence tactic affects the propensity to comply but not the amount given (Cialdini \& Schroeder, 1976; Guéguen, 2001; Hornik, 1988; Reeves \& Saucer, 1993; Reingen, 1978; Santos, Leve, \& Pratkanis, 1994). Our results suggest that the "evoking freedom" tactic extends the predisposition to comply, created by the influence tactic, by overcoming the inertia of just giving a minimum amount.

This first experiment reinforces the statement that adding that someone is free to do something is associated with a high probability of that person doing the given thing. Moreover, in order to confirm the efficiency of the "evoking freedom" technique and the generalization of this technique to various types of requests and behavior, additional experiments were performed. In Experiments 2-7, the effect of this technique on several solicitations addressed to strangers in the street was

Table 1 Frequencies of Participants Who Complied With the Request for Money and Amount of Donation in Experiment 1

\begin{tabular}{|c|c|c|c|}
\hline & "But you are free . . ." condition & Control condition & Total \\
\hline \multicolumn{4}{|l|}{ Request compliance } \\
\hline Male participants & $38.5 \%(n=540)$ & $15.4 \%(n=540)$ & $26.9 \%(n=1,080)$ \\
\hline Female participants & $42.8 \%(n=540)$ & $17.4 \%(n=540)$ & $30.1 \%(n=1,080)$ \\
\hline \multicolumn{4}{|l|}{ Total } \\
\hline Amount of donation ( $€$ convert in \$US) & $40.6 \%(n=1,080)$ & $16.4 \%(1,080)$ & $28.5 \%(2,160)$ \\
\hline \multirow[t]{2}{*}{ Male participants } & $M=1.71$ & $M=1.14$ & $M=1.55$ \\
\hline & $S D=0.53$ & $S D=0.62$ & $S D=0.56$ \\
\hline \multirow[t]{2}{*}{ Female participants } & $M=1.47$ & $M=0.95$ & $M=1.32$ \\
\hline & $S D=0.48$ & $S D=0.59$ & $S D=0.51$ \\
\hline \multirow[t]{2}{*}{ Total } & $M=1.58$ & $M=1.04$ & $M=1.42$ \\
\hline & $S D=0.50$ & $S D=0.60$ & $S D=0.53$ \\
\hline
\end{tabular}


tested. In Experiment 2, a commonplace solicitation (perhaps the most basic solicitation) was used to test the effect of the "evoking freedom" technique. Student smokers on a campus were solicited by a female confederate for a cigarette. Depending on the case, when asking the student for a cigarette the confederate stated, or not, that the smoker was free to accept or to refuse to give her a cigarette.

\section{Experiment 2: Expanding the "evoking freedom" tactic with a new dependent variable: giving a cigarette}

\section{Method}

\section{Participants}

The participants were 80 male and 80 female student smokers (approximately 18-22 years old) from the University of Provence. In France, the percentage of smokers in this age group is $43 \%$ for men and $38 \%$ for women (Mermet, 2010). They were solicited from various locations on the campus (e.g., cafeteria, park bench) to participate in one of the two experimental conditions ( 40 men and 40 women in each condition) according to the same method as described in Experiment 1.

\section{Procedure}

A young, casually dressed (20 years old; jeans, T-shirt) woman acted as the confederate. The study was conducted on the campus from 2:00 p.m. to 6:00 p.m. for 2 days. The confederate was instructed to test 80 passersby ( 40 men and 40 women) in the experimental condition and 80 passersby (40 men and 40 women) in the control condition. A confederate approached a participant after counting the passage of a definite number of pedestrians in a defined zone. If the subject was a child or a teenager or an elderly man/woman or a group, the confederate approached the person coming just after so that he/she corresponded to the expected profile (a man or a woman aged approximately 18-22 years old). The confederate was instructed to test two participants using the experimental request and then two participants using the control request. This alternation was used all along the experiment. When the confederate saw a potential participant (a young man/woman, seated alone and smoking a cigarette) she approached him/her and said: "Excuse me for disturbing you, but I have a favor to ask you. I have no cigarettes and I feel like smoking one. Could you please help me by giving me a cigarette?" This is what was said in the control condition, whereas in the experimental condition the confederate asked with the same tone: "Excuse-me for disturbing you, but I have a favor to ask you. But, obviously, you are free to accept or to refuse ('Mais, bien entendu, vous êtes libre d'accepter ou de refuser'). I have no cigarettes and I feel like smoking one. Could you please help me by giving me a cigarette?" The confederate recorded the behavioral response of the participant and a complete debriefing occurred. The confederate then gave the cigarette back to the participant who had agreed to give her a cigarette. The confederate then estimated if the participant agreed or not to her request and then proceeded to the participant's debriefing in the same way as in the first experiment.

\section{Results}

The numbers and percentages of participants who complied with the request for a cigarette addressed by the confederate are shown in Table 2.

Using the number of participants agreeing with the request, a log-linear analysis of the 2 (participant sex) $\times 2$ (experimental condition) $\times 2$ (compliance) design revealed a significant three-way interaction, $\chi^{2}(2, n=160)=12.38$, $p=.002$. A significant effect of the interaction between the experimental conditions and the participant's compliance with the request was found, $\chi^{2}(1, n=160)=4.43, p=.025$, $\varphi=.17$. More experimental participants $(85.0 \%)$ than control participants $(71.3 \%)$ complied with the request of the confederate. However, the positive effect of the "evoking freedom" technique was only found with female participants, $\chi^{2}(1, n=80)=5.70, p=.016, \varphi=.27$, whereas no significant difference was found with male participants, $\chi^{2}(1$, $n=80)=.13$, ns. The interaction between the participant's sex and the participant's compliance with the request was significant, $\chi^{2}(1, n=160)=10.57, p=.002, \varphi=.26$. Men were more eager to comply with the request than women $(88.8 \%$ vs. $67.5 \%)$.

\section{Discussion}

The data confirmed that with a request for a cigarette, adding a phrase in the verbal solicitation where the participant was free to accept or to refuse to give the cigarette was associated

Table 2 Frequencies of Participants Who Gave a Cigarette to the Confederate in Experiment 2

\begin{tabular}{lll}
\hline & "But you are free ..." condition & Control condition \\
\hline Male participants & $90.0 \%(n=40)$ & $87.5 \%(n=40)$ \\
Female participants & $80.0 \%(n=40)$ & $55.0 \%(n=40)$ \\
Total & $85.0 \%(n=80)$ & $71.3 \%(n=80)$ \\
\hline
\end{tabular}


with greater compliance. However, the "evoking freedom" technique seems to be only efficient with female participants. With the male participants, a ceiling effect occurred in the control condition. This effect is perhaps explained by the fact that the request was not a very costly request and because, traditionally, a request for help addressed by a woman to a man is associated with a greater level of compliance than the same request addressed by a woman to another woman (Bierhoff, 2002).

In spite of this ceiling effect associated with gender, this experiment confirms the efficiency of the "evoking freedom" technique for gaining compliance for a very usual and basic request. These new results, therefore, appear encouraging. The next experiment was conducted to pursue the generalization of the effect of this technique on various requests. However, in Experiment 3, precaution was taken to avoid a low-cost request for the person solicited. In this new experiment, several thousands of passersby in the street were solicited to participate in a survey that would take several minutes of their time. According to the experimental conditions, the request for participating was associated or not with the use of the classical phrase that the passerby solicited was free to accept or to refuse to answer the survey.

\section{Experiment 3: Testing the "evoking freedom" tactic with a moderately costly request: participating in a survey}

\section{Method}

\section{Participants}

The participants were 4,421 passersby (2,047 men and 2,374 women) with age approximately estimated from 25 to 70 years old, solicited in various streets of two towns (between 60,000 and 70,000 inhabitants) situated on the south coast of Brittany in France.

\section{Procedure}

A total of 104 confederates ( 48 men and 56 women) (average age 20-22 years old) were used in this experiment. All the confederates were undergraduate students in Business Management. The experiment was conducted during a period where a local newspaper solicited the business department and the undergraduate students to conduct a survey about the perception and the evaluation of the newspaper in the population. The confederates were neatly dressed and in a traditional way for young people of their age (jeans/sneakers/ T-shirt).

The experiment took place in the street, during particularly sunny spring days. Each investigator approached a participant who was alone. Confederates were instructed to solicit people walking in the street aged approximately between 25 and 70 years old. The confederates were instructed to solicit both men and women. They were also instructed to solicit three passersby using the request of the control condition and then three other passersby using the request of the experimental condition, and so on. In the control condition, the confederate approached the participant politely saying to him/her: "Excuse me sir/madam. We are currently conducting a survey on the perception of a local newspaper 'le Télégramme.' Would you agree to answer the questionnaire that will take 3-4 minutes?" In the experimental condition, with the same tone, the investigator formulated the same request in the following way: "Excuse me Madam/ Sir, I have something to ask you but you are free to accept or to refuse ('. . . mais vous êtes libre d'accepter ou de refuser'). We are currently conducting a survey on the perception of a local newspaper 'le Télégramme.' Would you agree to answer the questionnaire that will take 3-4 minutes?" Participants who refused were thanked. Those who complied were given the questionnaire to complete.

\section{Results}

The percentages and number of participants who complied with the request for survey addressed by the confederates are shown in Table 3.

With the number of participants agreeing with the request, a log-linear analysis of the 2 (participant sex) $\times 2$ (experimental condition) $\times 2$ (compliance) design revealed a significant effect of the interaction between the experimental conditions and the participant's compliance with the request, $\chi^{2}(1, n=4,421)=52.42, p<.001, \varphi=.11$. More experimental participants $(27.7 \%)$ than control participants $(18.5 \%)$ complied with the confederate's request. The interaction between the participant's sex and the participant's compliance with the request was significant, $\chi^{2}(1, n=4,421)=20.15, p<.001$, $\varphi=.07$. Men were more eager to respond to the survey than

Table 3 Frequencies of Participants Who Complied With the Survey Request in Experiment 3

\begin{tabular}{llr}
\hline & "But you are free ..." condition & Control condition \\
\hline Male participants & $31.1 \%(n=1,008)$ & $21.3 \%(n=1,039)$ \\
Female participants & $24.8 \%(n=1,175)$ & $16.1 \%(n=1,199)$ \\
Total & $27.7 \%(n=2,183)$ & $18.5 \%(n=2,238)$ \\
\hline
\end{tabular}


women (26.1\% vs. $20.4 \%)$. The third interaction analyzing the interaction between the experimental conditions, the participant's sex, and the participant's compliance revealed no interaction effect, $\chi^{2}(2, n=4,421)=0.48$, ns.

\section{Discussion}

The data confirmed that with a request for participation in a survey, adding a phrase in the verbal solicitation which emphasizes the person's free choice was associated with greater compliance. These data highlight the power of the "evoking freedom" technique in gaining compliance with a request. The effect size observed was all the greater because there were more than 4,000 participants and because the request was not, strictly speaking, low cost.

While the request in this experiment appears to be more costly than in the two previous experiments, it is qualified as a moderately costly request because only 3-4 minutes were necessary to respond to the questionnaire. It will be interesting to discover whether the "evoking freedom" tactic remains effective with more costly requests. To test this aspect and pursue our evaluation of the generalization of this technique to various requests, a further experiment was conducted in which passersby were first asked to view a video before responding to a questionnaire. As in the previous experiments, the request for participation included, or not, a phrase evoking participants' free choice.

\section{Experiment 4: Testing the "evoking freedom" tactic with two subsequent requests: viewing a video and participating in a survey}

\section{Method}

\section{Participants}

The participants were 60 passersby ( 25 men and 35 women) with age approximately $20-40$ years old, solicited in various streets of Bordeaux in France (350,000 inhabitants).

\section{Procedure}

The experiment took place during the presidential election campaign at the beginning of 2007. A young female confederate asked passersby to participate in a survey about the election. Participants were approached after counting the passage of a definite number of pedestrians in a defined zone. If the subject was a child or a teenager or an elderly man/woman or a group, the confederate approached the person coming just after so that he/she corresponded to the expected profile (a man or a woman aged approximately 20-40 years old). The confederate was instructed to test two participants using the experimental request and then two participants using the control request. This alternation was used through- out the experiment. The requester asked the participants first to view a 5-minute video presenting one of the candidates and displayed on a laptop computer, and then, after viewing the video, to respond to a questionnaire about the candidate. In the control condition, the confederate approached the participant politely saying to him/her: "Good morning Madam/ Sir. I am currently conducting a political survey. Would you agree to watch a 5-minute video and then answer a questionnaire?" In the experimental condition, the investigator formulated the following request with the same tone: "Good morning Madam/Sir. I am currently conducting a political survey. Of course, you are free to accept to participate or not ('Bien entendu, vous êtes libre de participer ou pas'). Would you agree to watch a 5-minute video and then answer a questionnaire?" The participants were approached with one of the two requests according to a previous random distribution. If the participant refused, the confederate thanked him/her. If he/she complied, then the confederate gave him/her a small laptop and explained to the participant how to proceed. Then the participant watched the video. The confederate was instructed to move away $(5 \mathrm{~m})$ and waited without looking at the participant until the video ended. Then the confederate came back to the participant, took back the laptop, and then filled out the questionnaire. All the participants who agreed to watch the video were fully debriefed.

\section{Results}

The number of participants who agreed to view the video clip and to respond to the survey was the only dependent variable in this experiment. It was found that in the experimental condition, $76.7 \%$ of the participants $(23 / 30)$ complied with the request whereas $33.3 \%$ (10/30) complied in the control condition. An independent chi-squared test analyzing the interaction between the experimental conditions and the participant's compliance with the request was performed and revealed significant interaction, $\chi^{2}(1, n=60)=11.38$, $p<.001, \varphi=.44$.

\section{Discussion}

Again, we found that a request accompanied by the phrase that stated that the participant was free to accept to participate or not is more efficient for gaining compliance with the request. Thus, with a more costly request, the "evoking freedom" technique still remained efficient for gaining compliance. However, in Experiments 1-4, we used requests in which help for someone was solicited. What would happen with the "evoking freedom" tactic in a selling context where the objective would be to get participants to purchase something?

To test the efficiency of the "evoking freedom" technique in a selling context, homeowners were solicited by confederates to buy crêpes, Breton pancakes. As in the preceding experi- 
ments, the request was or was not associated with a phrase emphasizing that the homeowners were free to accept or to refuse to buy the pancakes.

\section{Experiment 5: Testing the "evoking freedom" tactic in a selling context: buying pancakes}

\section{Method}

\section{Participants}

The participants were 400 residents (253 women and 147 men) of a middle-income suburban housing area in a middle-sized town (60,000 inhabitants) on the West Atlantic coast of France.

\section{Procedure}

The experiment was conducted during a period in which a charitable organization sold some products to collect money for a social action. Twelve pairs of confederates ( 20 years old; 14 men and 10 women) with identification badges for a charitable organization approached a home and addressed the first adult who came to the door. As in the previous experiment, each pair of confederates was instructed to test two participants using the experimental request and then two participants using the control request. This alternation was used throughout the experiment, creating 2 groups of 200 participants. After introducing themselves and the charitable organization, one of the two confederates presented his/her request. In the control condition the confederate stated, "We are collecting money for our organization by selling pancakes. A dozen pancakes costs 4.00 euros. Would you like to buy some?" In the experimental condition the confederate stated, "You are free to accept our solicitation or not ("Vous êtes libre d'accepter notre proposition ou pas mais ...' in French), but we are collecting money for our organization by selling pancakes. A dozen pancakes costs 4.00 euros. Would you like to buy some?" The dependent variable was the number of subjects who bought a dozen pancakes for both conditions. Because the experiment was conducted during a national humanitarian campaign, if the subject agreed, then the confederate took the money and gave him/her the product. The money collected at the end of the experiment was given to the charitable organization.

\section{Results}

The percentages and number of participants who complied with the request are presented in Table 4.

With the number of participants agreeing with the request, a log-linear analysis of the 2 (participant sex) $\times 2$ (experimental condition) $\times 2$ (compliance) design revealed only one significant effect, the interaction between the experimental conditions and the participant's compliance with the request, $\chi^{2}(1, n=400)=18.30, p<.001, \varphi=.21$. More experimental participants $(70.0 \%)$ than control participants $(49.0 \%)$ complied with the request of donation to the confederate. Women were slightly more eager to comply with the request than men ( $60.5 \%$ vs. $57.8 \%)$, but the difference was not statistically significant.

\section{Discussion}

Again, with a different type of solicitation than in the previous experiments, we found that the "evoking freedom" technique was efficient in gaining compliance with a request. Interestingly, it was found that this technique can be employed with success in a selling request. Of course, the nature of this selling request remained pro-social given the fact that the sale was a money collection to help a charitable organization. However, the dependent variable employed in this experiment still remains the same as in the previous experiment where the sale was not for the profit of a charitable organization but for the profit of a private company (Guéguen \& Jacob, 2005). This experiment seems to show that the "evoking freedom" technique is not efficient only with request for help and the new data confirm the powerful effect this technique has on various types of solicitation.

In the previous experiments, we found with multiple sorts of requests that the "evoking freedom" technique increased compliance. However, in these experiments, the participant performed the request immediately by responding to a questionnaire or donating some money. It will be interesting for social psychologists not only to strive toward the different types of requests affected by the "evoking freedom" technique, but also to evaluate the long-term effect of this technique. Most studies that have tested the effect of compliance tactics use short-term dependent variables where the technique precedes the request with a delay of about several seconds or minutes (Pratkanis, 2007). In contrast, long-term effects have rarely been tested with these techniques.

Table 4 Frequencies of Participants Who Complied With the Selling Request in Experiment 5

\begin{tabular}{llr}
\hline & "But you are free ..." condition & Control condition \\
\hline Male participants & $71.1 \%(n=76)$ & $31.7(n=71)$ \\
Female participants & $69.4 \%(n=124)$ & $51.9 \%(n=129)$ \\
Total & $70.0 \%(n=200)$ & $49.0 \%(n=200)$ \\
\hline
\end{tabular}


Therefore, to evaluate the possible long-term effects of the "evoking freedom" tactic, a new experiment was designed to determine whether people at home would agree to recording on a form their entire household waste for 1 month. Again, depending on the case, the request for participation during the first contact included, or not, a phrase stating the participant was free to accept or to refuse participation.

\section{Experiment 6: Evaluating the long-term effects of the "evoking freedom" tactic: monitoring household waste disposal for 1 month}

\section{Method}

\section{Participants}

The participants were 100 apartment owners (42 men and 58 women) of Bordeaux in France (350,000 inhabitants), aged between approximately 20-91 years old. The participants were solicited while they were at home.

\section{Procedure}

The experiment was conducted during a period in which several actions to promote recycling were conducted by the city of Bordeaux in France. A young female confederate went to the home of each participant. The confederate was instructed to test two participants using the experimental request and then two participants using the control request. This alternation was used throughout the experiment. After introducing herself, she stated, "Good morning/evening Sir/ Madam, I'm a student employed by the county to conduct a survey about the selective sorting of household waste." Then, in the control condition, the confederate added, "Would you agree to fill out a sorting book for one month in which the quantity of glass, plastic and paper will be registered? As often as you put waste in the trash, you will have to note the date and the quantity of waste, by weighing your garbage bags or by counting the number of bottles." In the experimental condition, the confederate used the same sentence but added at the end: ". . . by counting the number of bottles. Of course you are free to accept or to refuse" ("Bien entendu vous êtes libre d'accepter ou pas" in French). Those participants who refused were thanked by the confederate who then left.
Participants who agreed were given an instruction booklet and a sorting book in which they were to record their household waste. The confederate thanked the participant, indicating that she would return in 1 month to collect the sorting book. One month later, the confederate returned to the participant's home to get the sorting book. The confederate thanked the participant again. No debriefing was conducted at this point. After that, the confederate analyzed all the sorting books. A participant was considered a compliant if all the information appeared in the sorting book for each of the 30 days. If information was incomplete (no date reported) or performed only for 1, 2, or 3 weeks, then the participant was considered noncompliant.

\section{Results}

The numbers and percentages of participants who complied with the request of the confederate and who really carried out the behavior for 1 month are presented in Table 5 .

Three independent chi-squared tests analyzing the interaction between the experimental conditions and the participant's compliance with the request were performed. With the participants who first agreed to participate in the study, a significant interaction was found, $\chi^{2}(1, n=100)=6.82$, $p=.009, \varphi=.26$. Thus, more participants accepted to participate in the study in the "but you are free. .." condition than in the control condition. With the participants who carried out the behavior for 1 month, a Yates-corrected chi-squared test was used given the fact that there was an observed frequency lower than 10 in control condition. A significant effect was found when data took into account the initial sample size, $\chi_{\text {Yates }}^{2}(1, n=100)=8.19, p=.004, \varphi=.31$, or when data only took into account the number of participants who agreed with the request during the initial contact with the confederate, $\chi_{\text {Yates }}^{2}(1, n=55)=3.98, p=.05, \varphi=.31$. Thus, more participants carried out the expected behavior for 1 month in the "but you are free..." condition than in the control condition.

\section{Discussion}

The data confirmed that with a request for participating in a costly survey, adding a phrase in the verbal solicitation where the participant was free to accept or to refuse was associated with greater compliance. It was also found that the "evoking freedom" technique was associated with a long-term effect

Table 5 Frequencies of Participants Who Complied With the Request in Short and Long Terms in Experiment 6

\begin{tabular}{|c|c|c|c|}
\hline & "But you are free ..." condition & Control condition & Total \\
\hline Participants who first accepted to participate in the study & $68.0 \%(n=50)$ & $42.0 \%(n=50)$ & $55.0 \%(n=100)$ \\
\hline \multicolumn{4}{|l|}{ Participants who carried out the behavior for 1 month } \\
\hline With respect to the initial sample & $30.0 \%(n=50)$ & $6.0 \%(n=50)$ & $18.0 \%(n=100)$ \\
\hline With respect to the number of samples who accepted the request & $44.1 \%(n=34)$ & $14.3 \%(n=21)$ & $32.7 \%(n=55)$ \\
\hline
\end{tabular}


given the fact that it persisted 30 days after the acceptance of the request. Thus, our data confirmed the effect of the "evoking freedom" technique in order to gain compliance with a request and this effect does not seem limited to shortterm requests as in the previous experiments. The results also show that evoking freedom effected behavior related to participation (survey) or to donation (money). Many studies on influence tactics use such solicitations but their efficiency on further behaviors remains in question. In this experiment, we found that the "evoking freedom" tactic could be used in cases where we expected resistance from participants, for example, when someone is requested to maintain the same behavior over a longer period of time. Of course, this tactic has some practical implications for practitioners who want to change people's behaviors related with ecology.

To pursue our exploration of the effects of the "evoking freedom" tactic on various requests, a further experiment was designed to explore the nature of the interaction between the solicitor and the participant. Indeed, in the six previous experiments, face-to-face interaction was used between the requester and the participant solicited. Nevertheless, in everyday life, people receive solicitations that do not always involve face-to-face interaction.

The purpose of Experiment 7 was to test the effect of the "evoking freedom" technique in phone interaction. People at home were solicited by phone to participate in a survey. Depending on the case, the survey request was, or not, associated with a phrase that stated that the participants solicited by phone were free to accept or to agree to respond to the survey.

\section{Experiment 7: Evaluating the "evoking freedom" tactic in telephone communication: the phone survey}

\section{Method}

\section{Participants}

The participants were 2,289 people solicited at home (664 men and 1,625 women) with a mean age of 49.3 years $(S D=12.42)$. People were selected according to a drawing of people who appeared in phone books of two towns (between 60,000 and 70,000 inhabitants) situated on the south coast of Brittany in France.

\section{Procedure}

A total of 87 confederates ( 49 women and 38 men) (average age 20-22 years old) were used in this experiment. All the confederates were undergraduate students in Business Management. The experiment was conducted during a period where a laboratory for health research of the same university conducted a survey on people's eating habits. The assignment of a participant in one of the two experimental conditions was done according to a random choice. The experiment was carried out from 6:30 p.m. to 8:30 p.m. to increase the chances that people were at home after work.

When a participant was selected and assigned to one condition, the confederate dialed the phone number. If no one picked up, then the participant was called again the next day. After three tries without any contact, the participant was excluded from the sample. If contact occurred (if not, three attempts were made before removing the participant), then the confederate verified the identity of the participant: "Is this Ms. or Mr. X?” After confirmation, the confederate presented the request. In the control condition, the confederate said politely: "Sorry to disturb you Madam/Sir. The health department of the University of Bretagne-Sud is currently conducting a survey on the eating habits of people in your town. Would you agree to respond, by phone, to the questionnaire that will take you 3-4 minutes?" In the experimental condition, the confederate formulated the following request with the same tone: "Sorry to disturb you Madam/Sir, I have something to ask you, but you are free to agree or to refuse ( $~ . .$. mais vous êtes libre d'accepter ou de refuser'). The health department of the University of Bretagne-Sud is currently conducting a survey on the eating habits of people in your town. Would you accept to respond, by phone, to the questionnaire that will take you 3-4 minutes?" If the participant refused, the confederate thanked him/her and hung up. If he/she accepted, the questionnaire was administered. The questionnaire contained questions about the number of times per week the participant consumed fruits, vegetables, fishes, and so on. Age and other demographic information were also asked in the survey.

\section{Results}

The percentages and number of participants who complied with the request to participate in the phone survey addressed by the confederates are shown in Table 6.

Table 6 Frequencies of Participants Who Complied With the Phone Survey Request in Experiment 7

\begin{tabular}{lll}
\hline & "But you are free ..." condition & Control condition \\
\hline Male participants & $52.6 \%(n=481)$ & $36.5 \%(n=502)$ \\
Female participants & $69.5 \%(n=817)$ & $46.1 \%(n=808)$ \\
Total & $63.3 \%(n=1,298)$ & $43.7 \%(n=1,310)$ \\
\hline
\end{tabular}


With the number of participants agreeing to the request, a log-linear analysis of the 2 (participant sex) $\times 2$ (experimental condition $) \times 2$ (compliance) design revealed a significant effect of the interaction between the experimental conditions and the participant's compliance with the request, $\chi^{2}(1$, $n=2,608)=100.52, p<.001, \varphi=.19$. More experimental participants $(63.3 \%)$ than control participants $(43.7 \%)$ complied with the confederate's request. The interaction between the participant's sex and the participant's compliance with the request was significant, $\chi^{2}(1, n=2,608)=52.02, p<.001$, $\varphi=.14$. Women were more eager to respond to the survey than men (58.9\% vs. $44.4 \%)$. The third interaction analyzing the interaction between the experimental conditions, the participant's sex, and the participant's compliance revealed no interaction effect, $\chi^{2}(2, n=2,608)=1.53$, ns.

\section{Discussion}

The data confirmed that with a request for participating in a survey, adding a phrase in the verbal solicitation in which the participant was free to accept or to refuse to respond to the request was associated with greater compliance. These data confirmed the effect of the "evoking freedom" technique in order to gain compliance with a survey request even if the solicitation and the administration of the survey were done in phone-to-phone interaction. So these results seem to show that the effect of the "evoking freedom" technique does not require face-to-face interaction between the solicitor and the participants requested. Thus, in order to pursue this investigation of the nature of the interaction between the solicitor and the solicitee, another aspect of social interaction has been explored: the role of synchrony in the social exchange. In faceto-face or in phone-to-phone interaction, the exchange is synchronous and the two interlocutors can speak at the same time. Indeed, in face-to-face or in phone-to-phone interaction, a possible experimental bias could be associated with the use of the "evoking freedom" technique (additional gesture, longer eye contact, etc.). In spite of the precautions taken, a possible difference in the behavior of the confederate using the "evoking freedom" technique compared to the control condition still remains possible in face-to-face or in phoneto-phone interaction. It could therefore be interesting to conduct a study in which additional differences between the two experimental conditions are not possible. Mail or e-mail solicitation is a good opportunity to test the efficiency of the "evoking freedom" technique on people's behavior without any possible bias associated with the solicitor's behavior.

A previous experiment (Guéguen, LeGouvello, Pascual, Morineau, \& Jacob, 2002) has shown that in computermediated communication, the phrase "you are free" was associated with greater compliance with a request addressed by e-mail. In Guéguen et al.'s (2002) study, participants were sent electronic mail with the following message, "Would you give five minutes of your time for children in the world who are victims of mines?" An address for an HTML page was given with the e-mail. This page was blank except for a button that appeared on the top of the page. The following was written on the button: "Enter" for the control group, "Click here!" for the direct solicitation group, and "You are free to click here" for the "but you are free ..." indirect solicitation group. A hypertext link was associated with the button that permitted one to visit a website containing information about children who have been victims of mines all over the world. The semantic evocation of freedom was shown to be associated with a greater level of click on the website than in a situation in which this evocation was omitted.

The purpose of Experiment 8 was to confirm the effect of Guéguen et al.'s (2002) study by testing the influence of the "evoking freedom" technique in computer-mediated communication. Indeed, confirmation was necessary given the fact that in Guéguen et al.'s study, the sizes of the samples used were low and the phrase stating that people were free to click was not present in the main body of the text but written on a button. Unfortunately, the size of the button varied according to conditions and the larger button was present in the "evoking freedom" condition. Then, perhaps, the effect of the "evoking freedom" technique was not explained by the phrase per se but by the appearance of the button. So, in order to avoid this methodological bias and to evaluate the influence of the "evoking freedom" technique on more sizeable samples, a new experiment was carried out in which people received an electronic mail for visiting a website. Depending on the case, in the main body of the e-mail, the phrase that the receptor was free to visit the website was, or was not, added.

\section{Experiment 8: Evaluating the "evoking freedom" tactic in computer-mediated communication: the e-mailing request}

\section{Method}

\section{Participants}

The participants were 4,515 men and women registered in the database of a mailing list of a health association. They were selected to be in one of the two experimental conditions according to a random distribution. Given the fact that a high number of the e-mail addresses contained only surname or pseudo or gender ambiguous first names (i.e., Claude), it was not possible to classify all the participants according to their gender or their age group.

\section{Procedure}

Participants were sent electronic mail with the following message: "Tele-health: Who pays? Who receives? For what 
sort of services? A think tank is being organized in November 2007, the third under the aegis of the economical and social state department." Directly under this text, a sentence was added. In the control condition the sentence was "Look at the program and register," whereas in the experimental condition the sentence was "Feel free ('Sachez que vous êtes libre') to look at the program and register." The latter sentence was associated with a hypertext link that permitted the person to visit a website. Or course, a different website with a web counter was associated to the link. The dependant variable used in this experiment to test the participant's compliance was the number of participants who clicked on the hypertext link when the e-mail was sent to them.

\section{Results}

The number of participants who clicked on the hypertext link that took them to the website target was used as the only dependent variable in this experiment. In the experimental condition, 53 out of 2,258 participants clicked on the hypertext link, whereas 28 out of 2,257 participants did the same in the control condition. An independent chi-squared test analyzing the interaction between the experimental conditions and the participant's compliance with the request for visiting the website was performed and revealed significant interaction, $\chi^{2}(1, n=4,515)=7.85, p=.005, \varphi=.04$. This difference confirms that adding the phrase "feel free to do something ..." is associated with greater compliance with a request addressed in this computer-mediated social interaction.

\section{Discussion}

Once again, a phrase that contains words semantically related with freedom seems to be associated with greater compliance with a request. The data presented three interesting aspects. First, the results confirm the effect of the "evoking freedom" technique with a new type of request. Second, the data are congruent with the results of Guéguen et al. (2002) who also found that in a computer-mediated communication context, the effect of evoking freedom is associated with greater compliance with a request. Moreover, face-to-face interaction and synchronous interaction are not necessary for the "evoking freedom" technique to operate.

To continue our evaluation of the various modes of communication in which the "evoking freedom ..." tactic could be tested, another experiment was conducted in which the level of social interaction is low. Indeed, in face-to-face or phone-to-phone communications, the interaction is with someone who is physically present (face to face) or is associated with a form of social presence like in phone-to-phone interaction. In communication by e-mail, the cues of social presence are low but some other information associated with an interlocutor still remains present. For example, in the previous experiment, an e-mail address was used that contained the surname and the first name of a solicitor. It could be interesting to test the effect of the "evoking freedom" technique in a more informal social interaction than in computermediated communication. Thus, the context of a survey emanating from an anonymous organization and performed by mail would be the new mode of solicitation in which the "evoking freedom" technique would be tested. Participants received a survey on their eating habits by mail. According to the experimental conditions, the letter that accompanied the survey mentioned, or not, that participants were free to respond to the survey.

\section{Experiment 9: Evaluating the "evoking freedom" tactic in a one-way communication: the postal survey}

\section{Method}

\section{Participants}

The participants were 2,230 people (906 men and 1,324 women) who came from a database of a business website that proposed various products (e.g., clothes, household linen, small linen items) manufactured with organic materials. Participants were consumers who had previously ordered some products through the website. Their postal addresses were registered in order to deliver the products ordered on the website.

\section{Procedure}

Mail was sent out to named participants and consisted of a nonsigned cover letter, a four-page survey, and a preposted envelope to return the questionnaire. The survey was the same in both conditions but one sentence in the cover letter was added in the experimental condition. The sending of the two cover letters was performed according to a random distribution. The cover letter contained the name and address of the organization and explained in the first paragraph that the letter had been addressed to him/her because the receptor had bought a product on the website of the company in the last 12 months. The second paragraph explained that their company conducted a survey on their uses of organic products in their everyday lives. Then, the contents of the survey were briefly presented: a four-page survey evaluating the use and the frequencies of using organic or nonorganic products in their diet, personal hygiene, cosmetics, household uses, and so on. The manipulation of the experimental condition was done in the third paragraph. In the control condition, this paragraph was written as follows: "This survey is important for us to better understand our customers and to anticipate their consumption. Thus, we would like to thank you in advance for taking 2 or 3 minutes of your time to complete the survey, 
putting it in the pre-posted envelope and returning it to us." In the experimental condition, the paragraph began with the following sentence: "Of course, you are free to agree or to refuse to complete this questionnaire but this survey is important ..." ("Bien entendu vous êtes libre d'accepter ou de refuser ..."). The rest of the paragraph was exactly the same as the paragraph written in the control condition. A fourth paragraph appeared at the end of the cover letter and was the same in both conditions. This paragraph thanked the participants again for their help and their time. The cover letter ended with a first name and a surname and the function occupied by the requester in the organization. The signature appeared below the name. The dependent variable was the number of completed questionnaires returned by the participants 30 days after they had been sent off.

\section{Results}

The numbers and percentages of participants who returned the completed questionnaire are shown in Table 7.

With the number of participants agreeing with the request, a log-linear analysis of the 2 (participant sex) $\times 2$ (experimental condition $) \times 2$ (compliance) design revealed a significant effect of the interaction between the experimental conditions and the participant's compliance with the request, $\chi^{2}(1, n=2,230)=26.32, p<.001, \varphi=.11$. More experimental participants $(21.1 \%)$ than control participants (12.9\%) complied with the confederate's request. The interaction between the participant's sex and the participant's compliance with the request was significant, $\chi^{2}(1, n=2,230)=11.84, p=.001$, $\varphi=.07$. Here, women were more eager to respond to the survey than men $(19.3 \%$ vs. $13.7 \%)$. The third interaction analyzing the interaction between the experimental conditions, the participant's sex, and the participant's compliance revealed no interaction effect, $\chi^{2}(2, n=2,230)=3.61, n s$.

\section{Discussion}

Yet again, using the "evoking freedom" technique was found to be associated with greater compliance with a request. This effect occurred even if the quality of the social interaction between the solicitor and the participant was low, which was particularly the case in this experiment. So, again, these results seem to show that face-to-face interaction between the solicitor and the target of the request is not necessary. An epistolary relation by mail or by electronic mail still remains sufficient in obtaining a positive effect of a sentence that states that the receptor is free or not to comply with the request. This result is important because it seems to show that the efficiency of the technique is certainly related to the verbal contents of the request and to a different perception of the solicitor. Such an effect is congruent with a recent paper published by Joule, Girandola, and Bernard (2007). These authors stated that applying some statement of the commitment theory (Kiesler, 1971) is possible with some words or sentences in large media communication. Thus, it would be possible that people complied with the message contained in the communication. For these scientists, a message that states that people are free to perform a solicited behavior (e.g., the selective sorting of household waste) would be efficient in increasing the number of recipients who really performed the expected behavior. This type of communication is called by the authors "the commitment communication" and could be used easily in mail communication, radio communication, or in poster communication. Our last experiment is directly in line with some principles of the "commitment communication" given the fact that the message contained a phrase that led targets to agree more favorably to the request. Yet, saying that someone is free to perform an expected behavior is congruent with the argument of Kiesler and Sakumura (1966) that a way to increase the degree of commitment is to increase the degree of volition perceived by the individual in performing an act. It seems that writing in a letter that someone is free or not to participate in a survey request is a way of increasing this degree of commitment that is needed to affect behavior. Using the "evoking freedom" technique in a letter seems to be a good way to produce some "commitment communication."

In the nine previous experiments, we used various requests when examining the effect of the "evoking freedom" technique: "But you are free to accept or to refuse" in Experiments $1,2,3,6,7,9$; "You are free to accept to participate or not" in Experiment 4; "You are free to accept our solicitation or not" in Experiment 5; "Feel free to look at the program and register yourself" in Experiment 8. However, in all these multiple requests, the word "free" was present each time. So the question remains if it is the word "free" with all the symbolic connotations associated with it (e.g., this word is one of the first words that appear in the French Constitution) that explains the effect on compliance or if it is a feeling that the participant was free to comply that was activated by the larger phrase "but you are free to accept or to refuse.” To test this hypothetical

Table 7 Frequencies of Participants Who Complied With the Mail Survey Request in Experiment 9

\begin{tabular}{lll}
\hline & "But you are free ..." condition & Control condition \\
\hline Male participants & $16.8 \%(n=453)$ & $10.6 \%(n=453)$ \\
Female participants & $24.0 \%(n=662)$ & $14.5 \%(n=662)$ \\
Total & $21.1 \%(n=1,115)$ & $12.9 \%(n=1,115)$ \\
\hline
\end{tabular}


aspect, further experiments were carried out in which various language expressions that stated that someone is free to accomplish something but without using the word "free" were tested. Indeed, expressions such as "You are free" ("Vous êtes libre"), "Do as you wish" ("Faites comme vous voulez"), "Proceed as you like" ("Fait comme il vous semble"), "I don't want to oblige you” (“je ne veux pas vous obliger”), “That's up to you" ("C'est vous qui voyez"), etc. are frequent in the French language and in social interactions. Obviously, these expressions seem to have the same hidden sense and want to express that the person is free to act. Thus, the word "free" per $s e$ is not expected to explain the effect of the "evoking freedom" technique. Probably, phrases that mean that someone is free to comply with a solicitation, but without the use of the word "free," would also be efficient in increasing compliance. Therefore, greater compliance with a solicitation is also expected when using such familiar phrases in the verbal content of a request.

In order to test this hypothesis, a tenth experiment was carried out where the familiar expression in French language "do not feel obliged" was tested. Participants in the street were solicited for help. Depending on the case, the solicitor stated that the participant was "free to help or not" ("but you are free..." condition) or that he/she should "not feel obliged to help" ("do not feel obliged ..." condition). A control condition that did not use any of these two expressions was also carried out.

\section{Experiment 10: Testing two "evoking freedom" sentences: "You are free" vs. "Do not feel obliged"}

\section{Method}

\section{Participants}

The participants were 150 men and 150 women (estimated age range 25-55 years old), alone, chosen in the street of a town situated in the south of France, and with a population of about 150,000 inhabitants.

\section{Procedure}

A 20-year-old woman acted as a confederate. She was casually dressed like students of her age (jeans and T-shirt). The confederate approached a participant chosen at random after counting the passage of a definite number of pedestrians in a defined zone. If the passerby was a child or a teenager or an elderly man/woman or a group, the confederate took the person coming just after so that he/she corresponded to the expected profile (a man or a woman aged approximately 25-55 years old). In this experiment, three conditions were manipulated. In the control condition, the confederate approached the participant by saying to him or her politely: "Sorry to disturb you Madam/Sir, I have something to ask you. I absolutely need to take the bus and I have forgotten my purse. Could you please help me by giving me a bus-ticket or some change to buy a ticket?" In the "but you are free . . ." condition, the confederate asked the same request with the same tone. However, a sentence was added at the end of the request that stated: ". . . to buy a ticket? But obviously, you are free to help me or not" ("Mais, bien entendu vous êtes libre de m'aider ou pas"). In the "do not feel obliged ..." condition, the confederate asked the same request with the same tone, but a sentence was added at the end of the request that stated: ". . . to buy a ticket? But obviously do not feel obliged" ("Mais, bien entendu, ne vous sentez pas obligé").

The confederate then estimated if the subject agreed or not to her request. In the case of a positive answer, the confederate waited until the participant began to give her some money or a ticket and then proceeded with the debriefing, as in Experiment 1.

\section{Results}

The numbers and percentages of participants who offered help (some change or a ticket) to the confederate are shown in Table 8.

Using the number of participants agreeing with the request, a log-linear analysis of the 2 (participant sex $) \times 3$ (experimental condition) $\times 2$ (compliance) design revealed a significant effect of the interaction between the experimental conditions and the participant's compliance with the request, $\chi^{2}(2, n=300)=7.91, p=.02, \varphi=.16$. Comparisons between all the experimental conditions revealed that the "but you are free ..." condition was statistically different from the control condition, $\chi^{2}(1, n=200)=4.12, p=.04, \varphi=.14$, and that the "do not feel obliged . .." condition was statistically different from the control condition, $\chi^{2}(1, n=200)=7.43, p=.006$, $\varphi=.19$. However, the comparison of the "but you are free . ." condition and the "do not feel obliged ..." condition was not statistically different, $\chi^{2}(1, n=200)=0.50, n s$. The

Table 8 Frequencies of Participants Who Complied With the Request for Money in Experiment 10

\begin{tabular}{|c|c|c|c|c|}
\hline & "But you are free ... ." condition & "Do not feel obliged . . ." condition & Control condition & Total \\
\hline Male participants & $52.0 \%(n=50)$ & $58.0 \%(\mathrm{~N}=50)$ & $38.0 \%(n=50)$ & $48.7 \%(n=150)$ \\
\hline Female participants & $40.0 \%(n=50)$ & $46.0 \%(n=50)$ & $13.0 \%(n=50)$ & $37.3(n=150)$ \\
\hline Total & $46.0 \%(n=100)$ & $51.0 \%(n=100)$ & $32.0 \%(n=100)$ & $43.0 \%(n=300)$ \\
\hline
\end{tabular}


interaction between the participant's sex and the participant's compliance with the request was slightly significant, $\chi^{2}(1, n=300)=3.93, p=.05, \varphi=.11$. Here, men were more eager to help the female confederate than women $(48.7 \%$ vs. $37.3 \%)$. The third interaction analyzing the interaction between the experimental conditions, the participant's sex, and the participant's compliance revealed no interaction effect, $\chi^{2}(4, n=300)=0.78, n s$.

\section{Discussion}

In this experiment, the "evoking freedom" tactic was once again associated with greater compliance with the request. However, it was found that saying that someone should not feel obliged is also associated with greater compliance with the request for help. Moreover, no compliance difference between the "but you are free ..." condition and the "do not feel obliged ..." condition was found. These results are interesting because they seem to demonstrate that the efficiency of the "evoking freedom" technique employed throughout the nine previous experiments may not be explained by the presence of the word "free" per se in the phrase, but rather by the fact that both phrases ("you are free" and "do not feel obliged") are probably the capacity to activate the feeling that the participant is free to comply to the request, that he/she is not under pressure to comply. If some words or phrases have the capacity to activate such feelings, then these feelings possibly led the participant to comply with the request.

To test the generality of another usual phrase employed to create the feeling that someone is free to do something, another experiment was carried out using a basic expression used in our everyday solicitation: "do as you wish.” In this new experiment, people in the street were solicited for money. Depending on the case, the solicitation stated, or not, that the person solicited was free to help the solicitor or that the solicitor could do as he/she wished.

\section{Experiment 11: Testing two more "evoking freedom" sentences: "You are free" vs. "Do as you wish"}

\section{Method}

\section{Participants}

The participants were 129 men and 129 women (age range 25-55 years old), alone, chosen in the street of a town situated in the south of France (Aix-en-Provence), and with a population of about 150,000 inhabitants.

\section{Procedure}

A 20-year-old woman acted as a confederate. She was casually dressed like students of her age (jeans and T-shirt). The confederate approached a participant taken at random after counting the passage of a definite number of pedestrians in a defined zone. If the passerby was a child or a teenager or an elderly man/woman or a group, the confederate took the person coming just after so that he/she corresponded to the expected profile (a man or a woman aged approximately 25-55 years old). In this experiment, three conditions were manipulated. In the control condition, the confederate approached the participant by saying to him or her politely: "Sorry to disturb you Madam/Sir, I have something to ask you. I have no money with me and I need to take the bus. Could you please help me out? Would you have one euro, please?" In the "but you are free . . ." condition, the confederate asked her request with the same tone: "Sorry to disturb you Madam/Sir, I have something to ask you. But, obviously, you are free to help me or not. I have no money with me and I need to take the bus. Could you please help me out? Would you have one euro, please?" In the "do as you wish . . ." condition, the confederate again asked her request with the same tone: "Sorry to disturb you Madam/Sir, I have something to ask you. But, obviously, do as you wish ('Mais, bien entendu, faites comme vous voulez') I have no money with me and I need to take the bus. Could you please help me out? Would you have one euro, please?"

The confederate recorded whether the subject agreed or not and then debriefed the participant as in Experiment 1.

\section{Results}

The percentages and number of participants who offered EUR 1 to the confederate are shown in Table 9.

Using the number of participants agreeing to the request, a log-linear analysis of the 2 (participant sex) $\times 3$ (experimental condition $) \times 2$ (compliance) design revealed a significant effect of the interaction between the experimental conditions and the participant's compliance with the request, $\chi^{2}(2$, $n=258)=31.46, p<.001, \varphi=.33$. Comparisons between each experimental condition revealed that the "but you are free ..." condition was statistically different from the control condition, $\chi^{2}(1, n=172)=21.5, p<.001, \varphi=.33$, and that

Table 9 Frequencies of Participants Who Complied With the Request for Money in Experiment 11

\begin{tabular}{|c|c|c|c|c|}
\hline & "But you are free . . ." condition & "Do as you like ..." condition & Control condition & Total \\
\hline Male participants & $83.7 \%(n=43)$ & $81.3 \%(n=43)$ & $60.4 \%(n=43)$ & $75.2 \%(n=129)$ \\
\hline Female participants & $67.4 \%(n=43)$ & $72.1 \%(n=43)$ & $20.9 \%(n=43)$ & $52.7 \%(n=129)$ \\
\hline Total & $75.6 \%(n=86)$ & $76.7 \%(n=86)$ & $40.7 \%(n=86)$ & $64.3 \%(n=258)$ \\
\hline
\end{tabular}


the "do as you wish ..." condition was statistically different from the control condition, $\chi^{2}(1, n=172)=23.05, p<.001$, $\varphi=.34$. However, the comparison of the "but you are free. . ." condition and the "do as you wish ..." condition was not statistically different, $\chi^{2}(1, n=172)=0.03$, ns. The interaction between the participant's sex and the participant's compliance with the request was slightly significant, $\chi^{2}(1$, $n=258)=4.11, p=.05, \varphi=.11$. Here, again, men were more eager to help the female confederate than women $(75.2 \%$ vs. 52.7). The third interaction analyzing the interaction between the experimental conditions, the participant's sex, and the participant's compliance revealed no interaction effect, $\chi^{2}(4, n=258)=2.84$, ns.

\section{Discussion}

In this experiment, the "evoking freedom" tactic is yet again confirmed to be associated with greater compliance with a request for money. However, it was also found that the very usual expression in the French language "do as you wish" is also associated with a greater level of helping behavior. As no statistical difference was found between the "but you are free..." phrase and the "do as you wish . . ." phrase, it can be concluded again that it is not the presence of the word "free" that is associated with greater compliance but the meaning of the expressions such as "you are free," "do as you wish," "proceed as you like," "I don't want to oblige you," etc. Obviously, these various expressions seem to be associated with the feeling of freedom. When this feeling of freedom is activated, that leads the person solicited to agree more favorably with the request.

In the previous experiments, we have found that suggesting to someone that he/she is "free," "not obliged," etc. to perform a solicited helping behavior was associated with greater compliance with a request. We found that various semantically requests that were associated with the feeling that people were free to comply were all associated with greater later compliance. Experiments 10 and 11 found that the semantically inducing solicitation does not require that the phrase contain the word "free." However, when considering all the different experiments carried out, we found a methodological difference in the request. In some experiments (Experiments 2, 3, 4, $5,7,9$, and 11), the semantically freedom-inducing phrase was stated before the request was addressed to the participants, whereas in the other experiments (Experiments 1, 6, 8, and 10) the semantically freedom-inducing phrase appeared after the request for help was stated to the participant. In all experiments, we found that the "but you are free ..." or assimilated phrases were all associated with greater compliance with the request compared to a situation where these phrases were not presented in the request. However, the type of request or the type of participants used was not the same in all these experiments, and no systematic experiment examining the role of the part of the location the semantically freedom-inducing phrase was performed. So, it became interesting to test if this methodological aspect had an influence on the level of compliance. Kiesler and Sakumura (1966) considered that commitment to an act could be manipulated by different factors including the degree of volition perceived by an individual. These authors also assumed that the degree of commitment in performing an act would be increased by increasing the number of times each commitment factor was used. Repeating that someone is free to comply several times during the verbal solicitation is easy to implement. In the same way, according to the reactance theory (Brehm \& Brehm, 1981; Wicklund, 1974), people are not motivated to behave in a specific way if they think they are not free. Thus, if they perceive that they are acting of their own free will, they are less likely to be reluctant to perform the requested act. When the level of perceived freedom is high, more compliance is to be expected. As such, repeating that people are free to do as they choose several times during the request is likely to have led to increased perceived freedom and will presumably increase the likelihood of compliance.

So, we decided to test the effect of stating to someone that he/she is free to accept or to refuse twice during the solicitation: once before the request is stated and once while the request was stated. Stating twice that someone is free to accept or to refuse to help was expected to be associated with greater compliance than when the use of this semantically freedominducing phrase was stated only once.

To test this hypothesis, a 12th experiment was carried out in which the familiar expression in the French language "do not feel obliged" was tested again to replicate the findings found in the 10th experiment. In this experiment, the order of the freedom-inducing phrase in the request was tested to see if some differences existed if the phrase was stated before or after the request. Last, another experimental condition was introduced in which the freedom-inducing phrase was stated before and after the request for help. So, participants in the street were solicited for help. Depending on the case, the solicitor stated that the participants should "not feel obliged ...” to help. This phrase was placed before the request, during soliciting, or before and after the request. A control condition that did not use this expression before, after, or within the sentence was also carried out.

\section{Experiment 12: Testing the placement of the "evoking freedom" sentence: before or after the request}

\section{Method}

\section{Participants}

The participants were 200 men and 200 women (age range 25-55 years old), alone, chosen in the street of a town situated 
in the south of the France (Aix-en-Provence), and with a population of about 150,000 inhabitants.

\section{Procedure}

A 20-year-old woman acted as a confederate. She was casually dressed like students of her age (jeans and T-shirt). The confederate approached a participant chosen at random after counting the passage of a definite number of pedestrians in a defined zone. If the passerby was a child or a teenager or an elderly man/woman or a group, the confederate took the person coming just after so that he/she corresponded to the expected profile (a man or a woman aged approximately 25-55 years old). In this experiment, four conditions were manipulated. A total of 100 participants (50 men and 50 women) were tested in each condition. They were selected to be in one of the four experimental conditions according to a random distribution. In the control condition, the confederate approached the participant by saying to him or her politely: "Sorry to disturb you Madam/Sir, I have something to ask you. I absolutely need to take the bus and I have forgotten my purse. Could you please help me by giving me a bus ticket or some change to buy a ticket?" In the "do not feel obliged ..." conditions, the confederate said the same request with the same tone. However, a sentence was added to the request. Three conditions were performed. In the "do not feel obliged ..." phrase placed before the request, the confederate stated, "Sorry to disturb you Madam/Sir, I have something to ask you. But obviously do not feel obliged. I absolutely need to take the bus and I have forgotten my purse. Could you please help me by giving me a bus ticket or some change to buy a ticket?" In the "do not feel obliged ..." phrase placed after the request, the confederate stated, "Sorry to disturb you Madam/Sir, I have something to ask you. I absolutely need to take the bus and I have forgotten my purse. Could you please help me by giving me a bus ticket or some change to buy a ticket? But obviously do not feel obliged." Last, in the "do not feel obliged ..." phrase placed both before and after the request, the confederate asked, "Sorry to disturb you Madam/Sir, I have something to ask you. But obviously do not feel obliged. I absolutely need to take the bus and I have forgotten my purse. Could you please help me by giving me a bus ticket or some change to buy a ticket? But as I said, do not feel obliged."
The confederate then estimated if the subject agreed or not to her request. In the case of a positive answer, the confederate waited until the participant offered her some money or a ticket and then proceeded with the debriefing as in Experiment 1.

\section{Results}

The percentages and number of participants who offered some help (some change or a ticket) to the confederate are shown in Table 10.

With the number of participants agreeing to the request, a log-linear analysis of the 2 (participant sex) $\times 4$ (experimental condition $) \times 2$ (compliance) design revealed a significant effect of the interaction between the experimental conditions and the participant's compliance with the request, $\chi^{2}(3, n=400)=24.68, p<.001, \varphi=.24$. Comparisons between each of the three experimental conditions and the control condition revealed that the control condition was statistically different from the "do not feel obliged ..." phrase placed before the request, $\chi^{2}(1, n=200)=5.33$, $p=.02, \varphi=.16$; statistically different from the "do not feel obliged ..." phrase placed after the request, $\chi^{2}(1$, $n=200)=7.43, p=.006, \varphi=.19$; and statistically different than the "do not feel obliged ..." phrase placed both before and after the request, $\chi^{2}(1, n=200)=8.26, p=.004, \varphi=.19$. General comparison between the three experimental conditions revealed a significant difference, $\chi^{2}(2, n=300)=8.44$, $p=.02, \varphi=.15$. Comparisons between each of the three experimental conditions revealed that the "do not feel obliged ..." phrase placed both before and after the request was statistically different from the "do not feel obliged ..." phrase placed after the request, $\chi^{2}(1, n=200)=7.39$, $p=.007, \varphi=.19$, and statistically different from the "do not feel obliged ..." phrase placed before the request, $\chi^{2}(1$, $n=200)=5.29, p=.02, \varphi=.16$. However, no statistical difference was found between the "do not feel obliged ..." phrase placed before the request and the condition where the "do not feel obliged ..." phrase was placed after the request, $\chi^{2}(1, n=200)=0.18$, ns. The interaction between the participant's sex and the participant's compliance with the request was not significant, $\chi^{2}(1, n=400)=1.44$, $n s$. The third interaction analyzing the interaction between the experimental conditions, the participant's sex, and the

Table 10 Frequencies of Participants Who Complied With the Request for Money in Experiment 12

\begin{tabular}{|c|c|c|c|c|c|}
\hline & \multicolumn{3}{|c|}{ "Do not feel obliged . . ." conditions } & \multirow[b]{2}{*}{ Control condition } & \multirow[b]{2}{*}{ Total } \\
\hline & Before the request & After the request & Before and after the request & & \\
\hline Male participants & $50.0 \%(n=50)$ & $56.0 \%(n=50)$ & $66.0 \%(n=50)$ & $38.0 \%(n=50)$ & $52.5 \%(n=200)$ \\
\hline Female participants & $46.0 \%(n=50)$ & $46.0 \%(n=50)$ & $86.0 \%(n=50)$ & $26.0 \%(n=50)$ & $46.5 \%(n=200)$ \\
\hline Total & $48.0 \%(n=100)$ & $51.0 \%(n=100)$ & $67.0 \%(n=100)$ & $32.0 \%(n=100)$ & $48.5 \%(n=400)$ \\
\hline
\end{tabular}


participant's compliance revealed no interaction effect, $\chi^{2}(5$, $n=400)=3.29, n s$.

\section{Discussion}

With this new experiment, several important data were found. First, as in the 11th experiment, the use of another phrase to induce that the participant is free to agree to comply or not was found to be associated with greater compliance with the request. The effect of the phrase "do not feel obliged ..." still remains efficient in obtaining greater compliance with a request than the phrase "but you are free..." These results support the hypothesis that many different phrases that elicit freedom to comply are associated with positive efficiency. Thus, the term "evoking freedom" appears to be more appropriate for summarizing the influence of such sentences than the term "but you are free ..." initially used by Guéguen and Pascual (2000). Second, no effect was found in relation with the location that the freedom-inducing phrase was asked. The results showed that the efficiency of this freedom-inducing phrase was the same in both conditions. No specific hypothesis was stated about the place of the freedom-inducing phrase in the verbal request. The results of our previous experiments did not find any difference according to the fact that the semantically freedom-inducing phrase was stated before the request was addressed to the participants (Experiments 2, 3, 4, 5, 7, and 9) or after (Experiments $1,6,8$, and 10). The efficiency on compliance seemed to be the same in both conditions. However, the type of request or the type of participants used was not the same in these experiments and needed a systematic experiment that explored this aspect. This was done in this experiment and revealed that this variable seems to have no effect on compliance. Third, this experiment reveals that telling someone twice that he/she should not feel obliged to help is associated with greater compliance than saying it only once. These results, which now need replication, seem to show that a new compliance technique exists: the double "evoking freedom" technique and confirm the prediction stated by Kiesler and Sakumura (1966) that more commitment in performing an act could be obtained from individuals if factors that influence such commitment could be repeated. In accordance with such prediction, our data seem to show that stating the freedominducing phrase twice is really better than just once for gaining compliance.

To confirm the previous results, a 13th experiment was carried out with the objective of replicating the effect of the repetition of the semantically inducing-freedom phrases on compliance with a request. However, in this new experiment we decided not to repeat the same phrase before and after the request, but to state the phrases just one after the other. Of course, to proceed in this way, it was not possible to repeat the same phrase. So, in this experiment, two different phrases that have previously proven to be associated with greater compliance were stated one after the other.

Participants in the street were solicited for help. Depending on the case, the solicitor stated that the participants should "not feel obliged . . ." to help or were "free to help." In another condition, the phrases "But you are free to help ..." and "do not feel obliged" were stated in the same request in the latter after the former. A control condition that did not use any of these expressions was also carried out.

\section{Experiment 13: Testing two "evoking freedom" sentences in the same request: "You are free" plus "Do not feel obliged"}

\section{Method}

\section{Participants}

The participants were 200 men and 200 women (age range 25-55 years old), alone, chosen in the street of a town situated in the south of the France (Aix-en-Provence), and with a population of about 150,000 inhabitants.

\section{Procedure}

A 20-year-old woman acted as a confederate. She was casually dressed like students of her age (jeans and T-shirt). The confederate approached a participant chosen at random after counting the passage of a definite number of pedestrians in a defined zone. If the passerby was a child or a teenager or an elderly man/woman or a group, the confederate took the person coming just after so that he/she corresponded to the expected profile (a man or a woman aged approximately 25-55 years old). In this experiment, four conditions were manipulated. A total of 100 participants (50 men and 50 women) were tested in each condition. They were selected to be in one of the four experimental conditions according to a random distribution. In the control condition, the confederate approached the participant by saying to him or her politely: "Sorry to disturb you Madam/Sir, I have something to ask you. I absolutely need to take the bus and I have forgotten my purse. Could you please help me by giving me a bus ticket or some change to buy a ticket?" In the "do not feel obliged ..." condition, the confederate asked the same request with the same tone, "Sorry to disturb you Madam/Sir, I have something to ask you. But obviously do not feel obliged. I absolutely need . . ." (the end of the sentence was the same as before). In the "but you are free ..." condition the confederate stated: "Sorry to disturb you Madam/Sir, I have something to ask you. But you are free to help me or not. I absolutely need ..." (the end of the sentence was the same as before). Finally, in the "but you are free ..." + "do not feel 
obliged ...," the confederate said: "Sorry to disturb you Madam/Sir, I have something to ask you. But you are free to help me or not. Above all, do not feel obliged. I absolutely need ..." (again, the end of the sentence was the same as before).

The confederate then estimated if the subject agreed or not to her request. In the case of a positive answer, the confederate waited until the participant offered her some money or a ticket and then proceeded with the debriefing as in Experiment 1.

\section{Results}

The percentages and number of participants who offered some help (some change or a ticket) to the confederate are shown in Table 11.

With the number of participants agreeing with the request, a log-linear analysis of the 2 (participant sex) $\times 4$ (experimental condition $) \times 2$ (compliance) design revealed a significant effect of the interaction between the experimental conditions and the participant's compliance with the request, $\chi^{2}(3$, $n=400)=27.48, p<.001, \varphi=.26$. Comparisons between each of the three experimental conditions and the control condition revealed that the control condition was statistically different from the "do not feel obliged ..." condition, $\chi^{2}$ (1, $n=200)=6.85, p=.009, \varphi=.16$; statistically different from the "but you are free ..." condition, $\chi^{2}(1, n=200)=13.66$, $p<.001, \varphi=.26$; and statistically different from the "but you are free ..." "do not feel obliged ..." condition, $\chi^{2}(1$, $n=200)=25.65, p<.001, \varphi=.34$. Comparisons between each of the three experimental conditions showed that the "but you are free ..." + "do not feel obliged . . ." condition was statistically different from the "do not feel obliged . . ." condition, $\chi^{2}(1, n=200)=6.75, p=.009, \varphi=.18$. However the "but you are free ..." + "do not feel obliged ..." condition was not different from the "but you are free ..." condition, $\chi^{2}(1$, $n=200)=2.17, p=.14, \varphi=.10$. No statistical difference was found between the "do not feel obliged . . ." condition and the "but you are free . . " condition, $\chi^{2}(1, n=200)=1.29$, ns. The interaction between the participant's sex and the participant's compliance with the request was not significant, $\chi^{2}(1$, $n=400)=1.00$, ns. The third interaction analyzing the interaction between the experimental conditions, the participant's sex, and the participant's compliance revealed no interaction effect, $\chi^{2}(5, n=400)=1.51, n s$.

\section{Discussion}

With this new experiment, the results shown in Experiment 10 are confirmed. Both the "but you are free ..." phrase and the "do not feel obliged ..." phrase were associated with greater compliance than when neither of these phrases were added in the request. However, if both phrases increased compliance, no compliance difference between the "but you are free ..." phrase and the "do not feel obliged ..." phrase was found. Thus, it seems, once again, that these two phrases have the same efficiency in increasing compliance. The results of Experiment 12 are also confirmed. Using a request where the semantically freedom-inducing phrase was presented twice is associated with greater compliance with the request than when the semantically freedom-inducing phrase was used only once. In the previous experiment, this effect was observed when the two phrases were used before and after the request for money. Here, the same efficiency could be seen with the phrases stated one after the other. Such results seem to mean that repetition is more important to elicit greater compliance than the place where the phrase appeared. These new data also confirm that the effect of the repetition still remains the same when two different phrases are used. Indeed, in Experiment 12, the phrase "but you are free ..." was repeated twice, whereas in this new experiment, two different phrases were used with the same efficiency. Moreover, the difference between the "but you are free. .." + "do not feel obliged . . ." condition used here (69.0\%) and the "do not feel obliged ..." phrase placed before and after the request as in the previous experiment $(67.0 \%)$ was not statistically different, $\chi^{2}(1, n=200)=0.09$, ns. Then this similarity in the efficiency would probably mean that repetition is the only factor that could explain the effect on compliance. Using the same phrase or different phrases is associated with the same efficiency, as is the place where these phrases appeared in the request. The effect of the double "evoking freedom" technique seems to be contained only in the repetition.

\section{General discussion}

With nearly 18,000 participants tested in 13 experiments, this novel "evoking freedom" technique was found to increase the rate of compliance with various requests. Indeed, in the first set of experiments (Experiments 1-9) the technique was efficient in increasing the number of participants who agreed to

Table 11 Frequencies of Participants Who Complied With the Request for Money in Experiment 13

\begin{tabular}{|c|c|c|c|c|c|}
\hline & $\begin{array}{l}\text { "But you are free...." } \\
\text { condition }\end{array}$ & $\begin{array}{l}\text { "Do not feel obliged ..." } \\
\text { condition }\end{array}$ & $\begin{array}{l}\text { "But you are free ...." + "Do } \\
\text { not feel obliged ..." condition }\end{array}$ & Control condition & Total \\
\hline Male participants & $62.0 \%(n=50)$ & $50.0 \%(n=50)$ & $74.0 \%(n=50)$ & $32.0 \%(n=50)$ & $54.5 \%(n=200)$ \\
\hline Female participants & $56.0 \%(n=50)$ & $52.0 \%(n=50)$ & $64.0 \%(n=50)$ & $26.0 \%(n=50)$ & $49.5 \%(n=200)$ \\
\hline Total & $59.0 \%(n=100)$ & $51.0 \%(n=100)$ & $69.0 \%(n=100)$ & $29.0 \%(n=100)$ & $52.0 \%(n=400)$ \\
\hline
\end{tabular}


a request for money or cigarettes, to participate in a survey, or to purchase some pancakes for a charitable organization. This technique was also effective in convincing individuals to record their household waste on a form. Thus, these results seem to validate the strong efficiency of this compliance technique. In the second set of experiments, in which the mode of interaction between the requester and the person solicited was tested, the "evoking freedom" technique was associated with greater compliance with a request addressed by mail and through face-to-face, phone-to-phone, or computermediated interaction.

Such results confirm the power of some verbal contents on compliance with a request. Indeed, the effect of our semantic evocation of freedom that we called the "evoking freedom" technique is associated with the same efficiency to other verbal-inducing compliance techniques that exist in social psychology literature: the "even a penny helps" technique (Cialdini \& Schroeder, 1976), the "foot-in-the-mouth" procedure (Howard, 1990), or the "that's-not-all" technique (Burger, 1986). All these previous techniques have been replicated several times, as has been our new semantic compliance technique. This approach based on the semantic content of the request seems to be promising given the fact that such positive effects emphasize the power of verbal expressions or verbal rituals on social influence. Thus, it would be interesting for social psychologists to carry on this way to extend the repertoire of verbal techniques for gaining compliance.

Interestingly, Experiments 12 and 13 show that the use of a request in which the semantically freedom-inducing phrase was presented twice is associated with greater compliance with the request than when the semantically freedominducing phrase was used only once in the request. This effect was found either when the same phrase was used twice at different parts of the request (Experiment 12) or when two different phrases were used (Experiment 13). Such results confirm the assumption of Kiesler and Sakumura (1966) that using factors that enhance commitment several times could increase the degree of commitment to performing an act. Therefore, the empirical validity of such assumption was confirmed in our two later experiments.

\section{Explaining the efficiency of the "evoking freedom" technique}

Although the intent of this paper was to test the generalization, the efficiency, and the power of the "evoking freedom" technique, the results also gave some information to help explain why this technique operates on people's compliance.

Several theoretical factors could explain these results. First, politeness theory could explain the effect of the semantic evocation of freedom. According to Brown and Levinson (1987), politeness refers to phrasing one's remark so as to minimize face threat. Because a polite request is perceived as less threat- ening for the subject, this led to decrease his/her reactance and then increased compliance with the request. Howard (1990) reports the results of three field experiments that demonstrate that asking someone how they feel facilitates compliance with a charitable request similar to the request used in our fifth experiment (buying a cookie). The effect of this technique, which is called the "foot-in-the-mouth" effect, had been confirmed by several studies (Aune \& Basil, 1994; Dolinski et al., 2001; Fointiat, 2000). However, this technique, which used common greetings, was shown to be efficient only when the solicitor asked the individual how he/she felt, let him/her verbally respond, and then acknowledged that response. The foot-in-the-mouth technique is only efficient when the solicitor observes this greeting ritual. Perhaps, in our experiments, using the "evoking freedom" technique is considered as a form of greeting ritual that increases later compliance with the request.

The reciprocity theory (Gouldner, 1960) could also explain our results. Perhaps the semantic evocation of freedom used in our experimental conditions reflected consideration for the participant. Thus, the latter wanted to reciprocate this consideration by agreeing to the request of the solicitor. Several studies have found that this activation to reciprocate is a good technique to obtain compliance with a request for help (Pascual \& Guéguen, 2003; Regan, 1971). The effect of the well-known "door-in-the-face" technique is theoretically explained by reciprocity (Cialdini et al., 1975) given the fact that the requester retreats from the large request and then obligates the participant to also make a concession and to accept the second later request. With the "evoking freedom" technique, perhaps, the phrase "you are free to accept or to refuse" could be perceived by the receptor as a concession offered by the solicitor. With this phrase, the solicitor gives something to the target (an opportunity to accept or to refuse, the right to decide for himself/herself, etc.) which led the receptor to give something else in return: Here the only thing he/she could grant would be the request.

Finally, the commitment theory could be put forward to explain our results. Kiesler and Sakumura (1966) and Kiesler (1971) have stated that to obtain from someone their commitment to perform an expected act, it was necessary to increase the degree of commitment. For these authors, there are several ways to increase commitment, but one of the most important is to increase the degree of volition perceived by the individual in performing the expected behavior. Joule and Beauvois (1998) assessed that a single phrase that states that the participant is free or not to comply is sufficient to increase the degree of volition of the participant. Data obtained in our experiment confirm this statement by showing that, at least, three different phrases that state that someone is free to comply ("you are free to accept or to refuse ...," "do not feel obliged ...." "do as you wish ...") are each associated with greater compliance with a request. Moreover, a commitment 
explanation that states that the degree of volition perceived by the individual in performing the expected behavior is positively related with the probability to perform the expected act (Kiesler, 1971) could explain the results found in Experiments 12 and 13. Indeed, in both experiments, the use of a request where the semantically induced freedom phrase was presented twice was associated with greater compliance with the request than when the semantically induced freedom phrase was used only once. This effect was also found when two different phrases were used (Experiment 13) or when the same phrase was used twice at different parts of the request (Experiment 12). Such results could be predicted by arguing that the degree of volition is related to the degree of commitment to perform an expected behavior. Most likely, in our experiments, the degree of volition was higher in the double "evoking freedom" condition than in the single "evoking freedom" condition which was nevertheless higher than the control.

In contrast with degree of volition and commitment, psychological reactance can also be evoked to explain our results. Reactance occurs when someone perceives that his or her freedom of behavior is threatened or restricted. Reactance is aroused in various manners: social pressure to act, financial incentives to comply, and physical dominance. For Brehm (1966) and Brehm and Brehm (1981), reactance creates a negative tension state that motivates the individual to act in order to restore the threatened freedom. So, perhaps, when someone is solicited to help another person, the solicitation itself can create an aversive tension which, in return, could decrease the likelihood of compliance. When using the "but you are free..." phrase, this feeling that the freedom of behavior is threatened or restricted would not occur or would be marginal. Without such an aversive feeling, a higher likelihood of compliance would be obtained. In the same way, if perceived freedom is a condition for compliance, this level of freedom is likely to be higher when the solicitor repeats during the interaction that the participant is free to comply, which, in turn, led him/her to accept more favorably to comply with the request.
Of course, these various above-proposed explanations are still speculative and other experiments are now necessary to try to point out the processes or cognitive states activated by the semantic evocation of freedom when a request solicitation is addressed to someone.

The processes that underlie influence tactics are often polygenetic and a given technique involves multiple processes. The "evoking freedom" tactic is not likely to be an exception to this and several processes can be evoked to explain the efficiency of this new technique. For example, if evoking freedom reduces the level of reactance to comply with the request, on the opposite side, this evocation probably increases commitment to act. By this way, reduced reactance plus increased commitment could explain compliance to the request.

This opens new interesting issues for further studies to address. Social psychologists could also find in such techniques some applied opportunity. Indeed, most compliancegaining procedures assume that face-to-face interaction or phone-to-phone interaction is necessary to obtain an effect (Pratkanis, 2007). First, verbal compliance tactics such as the "evoking freedom" procedure could be used effectively in mail solicitation or perhaps in radio communication, or poster campaigns to reach very large samples or populations. Second, this innovative technique is easy to use given the fact that adding a short phrase with the evocation of freedom is sufficient. Third, evoking freedom can be used in a wide range of pro-social settings including fund-raising for charity, soliciting aid with research, compliance with regimes for one's own health or the health of our planet, compliance with road safety rules, and so on. For practitioners, this technique could offer an opportunity to affect the behavior of large samples without any additional cost than adding two or three words in a message.

\section{Acknowledgment}

The authors would like to thank two anonymous reviewers for their help to improve the final version of the paper.

\section{References}

Aune, K. R., \& Basil, M. D. (1994). A relational approach to the foot-in-themouth effect. Basic and Applied Social Psychology, 24, 546-556.

Bierhoff, H.-W. (2002). Prosocial behaviour. Hove: Psychology Press.

Brehm, J. W. (1966). A theory of psychological reactance. New York: Academic Press.
Brehm, S. S., \& Brehm, J. W. (1981). Psychological reactance. New York: Academic Press.

Brown, P., \& Levinson, S. C. (1987). Politeness: Some universals in language usage. Cambridge: Cambridge University Press.

Burger, J. M. (1986). Increasing compliance by improving the deal: The that's-not-all technique. Journal of Personality and Social Psychology, 51, 277-283.
Burger, J. M., Messian, N., Patel, S., del Prado, A., \& Anderson, C. (2004). What a coincidence! The effects of incidental similarity on compliance. Personality and Social Psychology Bulletin, 30, 35-43.

Cialdini, R. B., Cacioppo, J. T., Basset, R., \& Miller, J. A. (1978). Low-ball procedure for producing compliance: Commitment then cost. Journal of Personality and Social Psychology, 36, 463-476. 
Cialdini, R. B., \& Schroeder, D. A. (1976). Increasing compliance by legitimizing paltry contributions: When Even a Penny Helps. Journal of Personality and Social Psychology, 34, 599-604.

Cialdini, R. B., Vincent, J. E., Lewis, S. K., Catalan, J., Wheeler, D., \& Lee Darby, B. (1975). Reciprocal concessions procedure for inducing compliance: The door-in-the-face technique. Journal of Personality and Social Psychology, 31, 206-215.

Dolinski, D., Nawrat, M., \& Rudak, I. (2001). Dialogue involvement as a social influence technique. Personality and Social Psychology Bulletin, 27, 1395-1406.

Dunyon, J., Gossling, V., Willden, S., \& Seiter, J. S. (2010). Compliments and purchasing behavior in telephone sales interactions. Psychological Reports, 106, 27-30.

Enzle, M. E., \& Harvey, M. D. (1982). Rhetorical request for help. Social Psychology Quarterly, 45, 172-176.

Fointiat, V. (2000). "Foot-in-the-Mouth" vs. "Door-in-the-Face" requests. The Journal of Social Psychology, 140, 264-266.

Freedman, J. L., \& Fraser, S. C. (1966). Compliance without pressure: The foot-in-the-door technique. Journal of Personality and Social Psychology, 4, 195-202.

Gouldner, A. W. (1960). The norm of reciprocity: A preliminary statement. American Sociological Review, 25, 161-178.

Guéguen, N. (2001). Toucher et soumission à une requête : Réplications expérimentales en situation naturelle et évaluation de l'impact du statut. Revue Internationale de Psychologie Sociale, 14, 113-158.

Guéguen, N., \& Jacob, C. (2005). Nineending price and consumer behavior: An evaluation with a new price presentation. Psychological Reports, 96, 1121-1122.

Guéguen, N., LeGouvello, J., Pascual, A., Morineau, T., \& Jacob, C. (2002). Request solicitation and semantic evocation of freedom: An evaluation in a computermediated communication context. Perceptual and Motor Skills, 95, 208-212.

Guéguen, N., \& Pascual, A. (2000). Evocation of freedom and compliance: The "But you are free of ..." technique. Current Research in Social Psychology, 5, 264-270.

Hornik, J. (1988). Cognitive thoughts mediating compliance in multiple request situations. Journal of Economic Psychology, 9, 69-79.

Horvitz, T., \& Pratkanis, A. R. (2002). A laboratory demonstration of the fraudulent telemarketers' 1 -in-5 prize tactic. Journal of Applied Social Psychology, 31, 310-317.

Howard, D. J. (1990). The influence of verbal responses to common greetings on compliance behavior: The foot-in-themouth effect. Journal of Applied Social Psychology, 20, 1185-1196.

Joule, R.-V., \& Beauvois, J.-L. (1998). La soumission librement consentie. Paris: P.U.F.

Joule, R.-V., Girandola, F., \& Bernard, F. (2007). How can people be induced to willingly change their behavior? The path from persuasive communication to binding communication. Social and Personality Psychology Compass, 1, 493-505.

Joule, R.-V., Gouilloux, F., \& Weber, F. (1989). The lure: A new compliance procedure. The Journal of Social Psychology, 129, 741-749.

Kiesler, C. A. (1971). The psychology of commitment. Experiments liking behavior to belief. New York: Academic Press.

Kiesler, C. A., \& Sakumura, J. (1966). A test of a model for commitment. Journal of Personality and Social Psychology, 3, 349353.

Kleinke, C. (1977). Compliance to requests made by gazing and touching experimenters in field settings. Journal of
Experimental Social Psychology, 13, 218223.

Kleinke, C. (1980). Interaction between gaze and legitimacy of request on compliance in a field setting. Journal of Nonverbal Behavior, 5, 3-12.

Mermet, G. (2010). Francoscopie 2010. Paris: Larousse.

Pascual, A., \& Guéguen, N. (2003). Reciprocity rules and compliance to a request: An experimental evaluation in a natural setting. Psychology and Education: An Interdisciplinary Journal, 40, 16-19.

Pratkanis, A. R. (2007). The science of social influence. New York: Psychological Press.

Reeves, R. A., Macolini, R. M., \& Martin, R. C. (1987). Legitimizing paltry contributions: On-the-spot vs. mail-in-requests. Journal of Applied Social Psychology, 17, 731-738.

Reeves, R. A., \& Saucer, P. R. (1993). A test of commitment in legitimizing paltry contributions. Journal of Social Behavior and Personality, 8, 537-544.

Regan, D. T. (1971). Effects of a favor and liking on compliance. Journal of Experimental Social Psychology, 7, 627-639.

Reingen, P. (1978). On inducing compliance with requests. Journal of Marketing Research, 5, 96-102.

Santos, M. D., Leve, C., \& Pratkanis, A. R. (1994). Hey buddy, can you spare seventeen cents? Mindful persuasion and the pique technique. Journal of Applied Social Psychology, 24, 755-764.

Solomon, H., Zener-Solomon, L., Arnone, M., Maur, B., Reda, R., \& Roth, E. (1981). Anonymity and helping. The Journal of Social Psychology, 113, 37-43.

Van Baaren, R. B., Holland, R. W., Kawakami, K., \& Van Knippenberg, A. (2004). Mimicry and prosocial behaviour. Psychological Science, 14, 71-74.

Wicklund, R. A. (1974). Freedom and reactance. Oxford: Lawrence Erlbaum. 